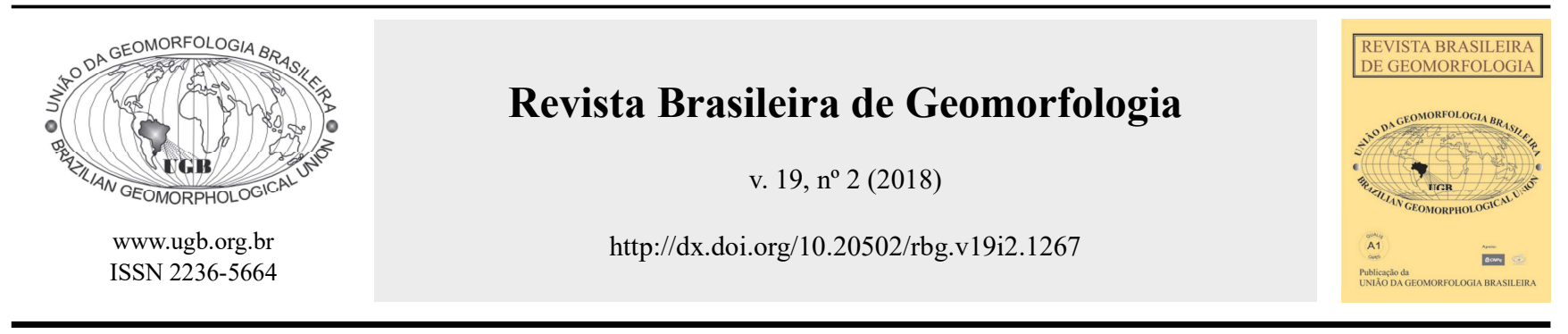

\title{
CARTOGRAFIA GEOMORFOLÓGICA REGIONAL E MORFOGÊNESE: CONTRIBUIÇÕES METODOLÓGICAS
}

\author{
REGIONAL GEOMORPHOLOGICAL CARTOGRAPHY AND \\ MORPHOGENESIS: METHODOLOGICAL CONTRIBUTIONS
}

\author{
Roberto Marques Neto \\ Departamento de Geociencias, Universidade Federal de Juiz de Fora \\ Rua José Lourenço Kelmer, S/N, Juiz de Fora, Minas Gerais. CEP: 36036-330. Brasil \\ E-mail: roberto.marques@ufjf.edu.br
}

Bernardo Valente Ferraro

Departamento de Geociências, Universidade Federal de Juiz de Fora Rua José Lourenço Kelmer, S/N, Juiz de Fora, Minas Gerais. CEP: 36036-330. Brasil

E-mail: bernardoferraro@gmail.com

\section{Informações sobre o Artigo}

Recebido (Received):

31/10/2017

Aceito (Accepted):

$15 / 12 / 2017$

\section{Palavras-chave:}

Cartografia Geomorfológica; Mapeamento Regional do Relevo; Depre-sões Interplanálticas; Serra da Mantiqueira.

\section{Keywords:}

Geomorphological Cartography; Regional Relief Mapping; Interplanal Depressions; Mantiqueira Mountain Range.

\begin{abstract}
Resumo:
A cultura geomorfológica brasileira padece de uma falta de uniformização na representação cartográfica do relevo, o que tem resultado em diversas propostas metodológicas desarticuladas. A necessidade de se integrarem em um mesmo documento cartográfico elementos morfológicos, morfométricos, morfodinâmicos, morfoestruturais e morfocronológicos dificulta que se firme uma metodologia a ser adotada em todos os projetos cartográficos. Seria salutar um avanço em demanda a uma linguagem cartográfica similar aplicável a diferentes escalas, sobretudo nas escalas regionais, estratégicas para um mapeamento sistemático. Em caráter mais oficial, conheceu expressiva difusão as propostas metodológicas construídas ao longo dos anos de execução do Projeto RADAMBRASIL, bem como aquela desenvolvida no âmbito do Instituto Brasileiro de Geografia e Estatística (IBGE). $\mathrm{O}$ presente trabalho atina especificamente à interpretação e representação do relevo em escala regional, e, a partir de uma abordagem integrada das duas propostas metodológicas supracitadas, apresenta uma proposta de mapeamento geomorfológico para a Folha Juiz de Fora, na escala de 1/250.000, como aporte à interpretação da morfogênese regional.
\end{abstract}

\begin{abstract}
:
The Brazilian geomorphologic culture suffers of a lack of uniformization in the cartographic representation of the relief what has being resulting in various disarticulate methodological propositions. The need of integrating in the same cartographic document morphologic, morphometric, morphodynamic, morphostructural and morphocronologic elements makes it difficult to firm a methodology to be adopted in all the cartographic projects. It would be salutary an improvement in demand to a similar cartographic language applicable to different scales especially to regional scales that are strategic for a systematic mapping. In a more official character the methodological propositions constructed during the years of execution of the Project RADAMBRASIL found expressive diffusion as well as
\end{abstract}


the one developed in the scope of Instituto Brasileiro de Geografia e Estatística (IBGE). The present work aims specifically to the interpretation and representation of the relief in a regional scale and from an integrated approach of the two methodological propositions above mentioned presents a proposition of geomorphological mapping for Folha Juiz de For a in the scale of $1 / 250,000$ as a contribution to the interpretation of the regional morphogenesis.

\section{Introdução}

A respeito da falta de consenso e de uniformização metodológica para a cartografia geomorfológica historicamente estabelecida entre os geomorfólogos brasileiros, a pauta já é desgastada, e a dificuldade em se integrar elementos morfológicos, morfogenéticos, morfométricos, morfodinâmicos, morfoestruturais e morfocronológicos em um mesmo documento cartográfico também é concorde, tanto no que concerne às possibilidades gráficas como no que se refere à geração dos dados, fundamentalmente os cronológicos. Sabe-se ainda, diante disso, que dificilmente a inserção destes elementos se efetiva de forma equitativa e equalizada, e comumente alguns deles são sub-representados em detrimento de outros, cuja representação apresenta menos complicações e admite uma maior desenvoltura.

Por exemplo, as geoformas, ou mesmo os padrões de formas semelhantes (sensu ROSS, 1992) ou sistemas de relevo, que perfazem os aspectos morfológicos, podem ser facilmente representados mediante procedimentos de compartimentação a partir de delimitação e uso de cores ou família de cores para representação dos tipos genéticos (denudacionais, agradacionais, de dissolução, etc.). Aspectos morfométricos como a dimensão interfluvial e a profundidade de dissecação também admitem representação resoluta com a inserção dos seus respectivos índices numéricos sobre as formas ou padrões de formas e apresentação de matrizes de dissecação na legenda. Por outro lado, a representação de dados geocronológicos é mais dificultosa, tendo que se recorrer, quase sempre, às datações relativas, como a diferenciação de planícies fluviais (ou costeiras) ativas holocênicas e terraços fluviais (ou flúviomarinhos) pleistocênicos, ou ainda às aproximações cronológicas dos somitais de altas cristas e chapadas do Cenozoico Inferior a partir da existência de bancadas lateríticas preservando paleosuperfícies. A inserção de aspectos morfoestruturais também costuma ser embaraçosa, sobretudo a representação dos diferentes litotipos, cuja manifestação areolar configura outro plano de informação sobreposto aos compartimentos do relevo, e o uso de hachuras, embora viável em algumas representações, por vezes tende a poluir o mapa em demasia. O mesmo motivo dificulta a representação das coberturas superficiais, sendo os aspectos morfodinâmicos abordados a reboque dos aspectos morfométricos e da energia do relevo que se deduz a partir de sua leitura, ou incorporados com o uso de símbolos. Elementos estruturais como escarpas de falha, suturas e zonas de cisalhamento com expressão no relevo também podem ser representados pelo recurso da simbolização. Sempre que os atributos tem distribuição contínua, é esperado que os diferentes layers se sobreponham, o que demanda o estabelecimento de um fundo como matriz e a incorporação das demais informações a partir de outros recursos gráficos.

As representações regionais admitem certa generalização da informação, mas também exigem uma organização normativa que seja capaz de definir de forma resoluta as prioridades de representação e a forma pela qual a informação será obtida e organizada. Nesse sentido, é salutar que a cartografia geomorfológica em escala regional seja construída a partir de um princípio de uniformização dos métodos de interpretação e técnicas de representação, fundamental no estabelecimento de correlações regionais proficientes, correlações estas que dependem, indubitavelmente, das iniciativas de coberturas de grandes áreas, referenciadas em espacialidades que refletem, de fato, a manifestação de diferentes regiões geomorfológicas e de seus aspectos morfogenéticos principais.

Por conseguinte ao exposto, a cartografia geomorfológica regional dá o mote do presente artigo, que apresenta uma proposta de mapeamento geomorfológico para a Folha Juiz de Fora (figura 1), em escala de $1 / 250.000$, adotada em função de sua aptidão em abranger organizações que refletem de fato o regional, congregando diferentes regiões geomorfológicas distribuídas em uma área de $18.315 \mathrm{~km}^{2}$ compreendida entre as coordenadas UTM 7570000/768000 latitude Sul e 660000/810000 longitude Oeste (23S). A proposta de mapeamento apresentada foi levada a efeito a partir de uma abordagem integrada entre duas proposições de signos oficiais na geomorfologia brasileira: a desenvolvida ao longo dos anos de execução do 
Projeto RADAMBRASIL, capitaneada por Getulio Vargas Barbosa e resumida por Barbosa (1983) em suas diferentes fases, e aquela elaborada no âmbito do Instituto Brasileiro de Geografia e Estatística (IBGE) (NUNES et al. 1994). Subsequentemente, são discutidos aspectos da morfogênese regional a partir do aporte dado pela cartografia geomorfológica, ressaltando a propriedade desse complexo recurso técnico em subsidiar estudos acerca da dinâmica e evolução do relevo. Sumarizando, a presente comunicação encerra dois objetivos dados (1) pela proposição de um mapa geomorfológico para a área de estudo como fomento ao desenvolvimento metodológico da cartografia geomorfológica regional e (2) pela discussão de aspectos morfogenéticos da área em questão em apreço ao papel da cartografia geomorfológica como ferramenta para a interpretação da gênese e dinâmica dos sistemas geomorfológicos.

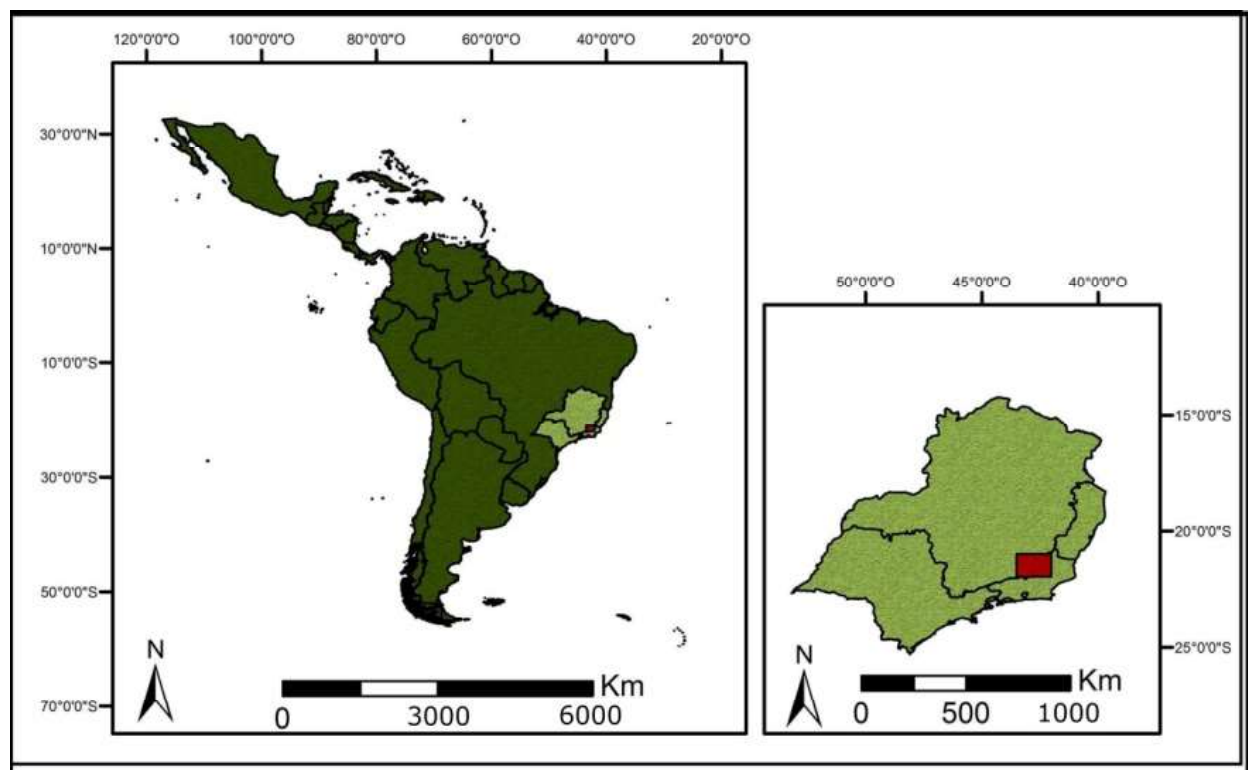

Figura 1 - Localização da Folha Juiz de Fora (retângulo vermelho).

\section{Procedimentos metodológicos}

No contexto brasileiro, o desenvolvimento metodológico da cartografia geomorfológica tem encarnado orientações de geomorfológos estrangeiros, entre os quais o francês Jean Tricart foi um dos mais influentes (TRICART, 1965); seu sistema taxonômico, facilitador ao raciocínio de compartimentação do relevo a partir da escala e dos respectivos cortes têmporoespaciais envolvidos em sua gênese e esculturação, foi incorporado e adaptado em propostas metodológicas de envergadura, como a de Ross (1992) e do próprio Projeto RADAMBRASIL, do qual o autor citado participou. A partir do referido projeto, portanto, se estabelece uma sistemática para o mapeamento do relevo brasileiro, criando-se nomenclaturas para uma miríade de compartimentos geomorfológicos regionais.

O primeiro nível de abordagem inerente ao protocolo metodológico da presente proposta se estabeleceu na compartimentação regional do relevo a partir das proposições do Projeto RADAMBRASIL (GATTO et al. 1983; BARBOSA, 1983) no âmbito taxonômico das regiões geomorfológicas e das unidades geomorfológicas, sendo este último táxon readaptado com base em interpretações mais detalhadas do relevo regional. Em seguida, as unidades geomorfológicas foram dissociadas em um terceiro nível taxonômico para discernir diferentes unidades que se integralizam com o ganho em detalhe logrado pela escala trabalhada, como depressões interplanálticas definidas por níveis de base distintos. A partir deste último nível foram diferenciados, em um quarto táxon, os seguintes tipos genéticos agrupados em sistemas de relevo ou padrões de formas semelhantes (ROSS, 1992): Modelados de Agradação (A), Modelados de Dissecação em Controle Estrutural (DE) e Modelados de Dissecação Homogênea (D) (quadro 1). Através dos tipos genéticos, portanto, diferenciam-se os modelados segundo sua morfogênese, discernindo-se aqueles cujo vínculo genético está ligado a processos deposicionais das morfologias de gênese tectono-erosiva. 
Quadro 1: Organização taxonômica elaborada para o mapeamento geomorfológico da Folha Juiz de Fora - 1/250.000.

\begin{tabular}{|c|c|c|}
\hline $\begin{array}{c}\text { NÍVEL } \\
\text { TAXONÔMICO }\end{array}$ & $\begin{array}{c}\text { INTEGRIDADE } \\
\text { GEOMORFOLÓGICA }\end{array}$ & $\begin{array}{c}\text { EXEMPLOS QUE OCORREM NA } \\
\text { FOLHA }\end{array}$ \\
\hline $1^{\circ}$ Táxon & Região Geomorfológica & Vale do Paraíba do Sul \\
\hline $2^{\circ}$ Táxon & Unidade Geomorfológica & $\begin{array}{c}\text { Depressões Interplanálticas do Vale do } \\
\text { Paraíba do Sul }\end{array}$ \\
\hline $3^{\circ}$ Táxon & Subunidade Geomorfológica & $\begin{array}{c}\text { Depressão do Rio Pomba, Depressão do } \\
\text { Rio Muriaé, etc. }\end{array}$ \\
\hline $4^{\circ}$ Táxon & $\begin{array}{l}\text { Modelados: tipos genéticos } \\
\text { denudacionais e agradacionais }\end{array}$ & $\begin{array}{l}\text { Modelados de Dissecação Homogêna: } \\
\text { morros, morrotes, colinas. }\end{array}$ \\
\hline
\end{tabular}

Estabelecidos os tipos genéticos, a diferenciação das diversas morfologias denudacionais se apoiou, a priori, na delimitação deáreas em imagens de satélite Landsat (bandas 5,4,3) e radar da missão SRTM (Shuttle Radar Topography Mission), geradas em dois ângulos de iluminação azimutal $\left(90^{\circ}\right.$ e $\left.315^{\circ}\right)$ para um realçamento mais abrangente dos alinhamentos ocorrentes. Os comportamentos texturais tendencialmente isotrópicos ou anisotrópicos permitiram uma primeira distinção entre os modelados de dissecação homogênea e em controle estrutural. A rotina voltada para a compartimentação dos padrões de formas foi completada por tratos morfométricos estabelecidos pela mensuração da profundidade de dissecação e da dimensão interfluvial, procedimento acompanhado da organização de uma matriz de dissecação, conforme levado a efeito por Nunes et al. (1994) e Cunha (2012), apresentada na legenda do mapa. Os referidos parâmetros morfométricos foram mensurados, em metros, nas folhas topográficas em escala de 1/50.000 para um controle mais estreito na definição dos conjuntos de formas. A incisão vertical foi quantificada a partir do estabelecimento da amplitude altimétrica entre os topos e fundos de vale de referência, ao passo que a dimensão interfluvial foi obtida pela medição da extensão da faixa divisória verificável entre as linhas de drenagem posicionadas na base de duas vertentes opostas ou entre dois pontos de surgência hídrica referenciados pelas nascentes dos canais de $1^{\circ}$ ordem marcadas nas folhas topográficas. Em seguida, conjuntos morfometricamente similares foram agrupados para que fosse levada a efeito a generalização necessária para a cartografia na escala de $1 / 250.000$.

O segundo nível de abordagem consistiu no desenvolvimento e inserção de símbolos para representação de aspectos estruturais e morfodinâmicos, fundamentalmente, e que permitem a representação de fatos geomórficos apreciáveis em níveis taxonômicos mais detalhados. Os relevos simbolizados partilham do protocolo metodológico de Nunes et al. (1994), procedimento este recorrente no cardápio metodológico da cartografia geomorfológica e bastante valorizado por autores como Tricart (1965), Nunes et al. (1994), Gustavsson e Kolstrup (2009) e Cunha (2012). Alguns fatos geomórficos, como faixas de meandros abandonados, foram simbolizados a partir de seus agrupamentos em função de um padrão de ocorrência concentrada e da inviabilidade escalar em representar tais geoformas em sua unidade, conforme orientado por Verstappen (1983). Os símbolos foram desenvolvidos segundo os recursos gráficos disponíveis do software ArcGIS.

Finalmente, um terceiro nível de abordagem se ocupou da organização cartográfica em meio digital das informações geradas. O produto cartográfico foi digitalizado em software ArcGIS, sendo aqui apresentado em quatro partes (quadrantes NW, NE, SE e SW) em função do tamanho da área, cuja apresentação cartográfica em sua unidade não é viável em corpo de artigo.

A legenda, em função de suas grandes dimensões, é apresentada em figuras a parte, também em quatro separatas para que tivesse sua leitura viabilizada. A composição de sua estrutura organizou hierarquicamente os níveis taxonômicos a partir das regiões geomorfológicas até os táxons subordinados a cada região. Para a representação dos modelados de dissecação homogênea, que perfazem as maiores expressões espaciais da folha, foram estabelecidas famílias de cores para o terceiro táxon e cores únicas para os tipos genéticos ( $4^{\circ}$ táxon), cujos sistemas de relevo foram diferenciados pelos símbolos alfanuméricos indicativos das formas predominantes e seu padrão de dissecação. Os tons de verde foram usados para a representação dos relevos mamelonizados do vale do Paraíba em suas depressões interplanálticas, as tonalidades vermelhas para os morros de dissecação mais profunda da Mantiqueira e 
os tons de pasteis para as morrarias e colinas do Planalto de Campo das Vertentes. Os modelados de dissecação em controle estrutural tiveram suas cores diferenciadas conforme o táxon superior ao qual pertencem, utilizandose tons de cinza para as cristas residuais contidas nas depressões do vale do rio Paraíba do Sul, tons de vermelho para os pilares tectônicos da Mantiqueira e magenta para os degraus da Serra dos Órgãos. Quanto às morfologias agradacionais, forjadas fundamentalmente em depósitos quaternários descontínuos e de fácies recorrentes, optouse por uniformizar as tonalidades amarelas para toda a área de mapeamento. Os conjuntos de tipos genéticos contidos em cada unidade ou subunidade geomorfológica são textualizados na legenda, adicionando-se detalhes aos seus aspectos morfológicos e informações estruturais e cronológicas.

A legenda se completa com a inserção da matriz de dissecação e dos demais símbolos, adicionandose informações morfométricas, morfoestruturais e morfodinâmicas. A referida matriz apresenta a lógica do trato morfométrico organizado em índices binários e espacializados pelo uso de símbolos nos diferentes compartimentos, conforme descrito. Pelo cruzamento dos valores de dimensão interfluvial e profundidade de dissecação foram derivadas informações de caráter morfodinâmico estabelecidas em 25 correlações possíveis, nas quais o cruzamento 11 denota o que consubstanciaria a mais baixa fragilidade (dimensão interfluvial muito grosseira e entalhe vertical muito fraco) e o cruzamento 55 a situação mais aguda quanto ao quadro de fragilidade (dimensão interfluvial muito fina e entalhe vertical muito forte). Por fim, os símbolos acrescentam informações morfoestruturais (vales estruturais, escarpas, cristas assimétricas) e morfodinâmicas, como faixas de abandono de meandros e ilhas fluviais.

As campanhas de campo cruzaram transversalmente as demais etapas de trabalho, tendo sido levado a efeito nas diferentes fases de abordagem, subsidiando desde as compartimentações iniciais até as interpretações específicas perpetradas na escala de observação, que quando exequíveis foram incorporadas ao mapa na forma de símbolos. Em função das dimensões significativas da área de estudo a sistemática de campo priorizou as ambulações mais gerais e abrangentes em detrimento das observações específicas, buscando estabelecer congruências com a própria generalização aceitável no âmbito de um mapeamento regional. As observações em detalhe foram realizadas de forma amostral ao longo das diferentes subunidades, e se ocuparam fundamentalmente de averiguar elementos da estrutura superficial da paisagem, procurando identificar os solos predominantes, os tipos de alteração vigentes e a profundidade dos mantos de intemperismo. Em campo foram ainda georreferenciados em GPS fatos geomórficos pontuais interessantes ao mapeamento e passíveis de conversão gráfica para geração de simbologia coerente, inseridos no mapa a partir de suas coordenadas em UTM.

\section{Resultados e discussões}

\section{A compartimentação geomorfológica regional}

A cartografia geomorfológica regional encontra campo de reflexão no debate conceitual acerca do significado dos termos "land surface", que são expressões morfológicas contínuas que cobrem todo o orbe, e "landform", por sua vez designativos de segmentos limitados e descontínuos da superfície terrestre, cuja definição é essencial para o mapeamento geomorfológico, diferindo-se de outros fatos geomórficos de manifestação linear (linhas de falha, linhas de ruptura de declive, lineamentos estruturais) e pontual (cumes, abismos, cavidades) por sua tridimensionalidade e volumetria bem marcada (EVANS, 2012). Inexoravelmente, os esquemas regionais de representação do relevo se voltam para interpretação tanto de fatos geomórficos tridimensionais, para os quais é dado, em geral, o trato morfométrico, e outros de manifestação linear e pontual, todos eles distribuídos ao longo de uma determinada extensão da superfície terrestre integralizada pela conjugação de tais objetos geomorfológicos.

A Folha Juiz de Fora (1/250.000) projeta o regional e consubstancia francamente a lógica supraexposta, congregando importantes sistemas geomorfológicos do Brasil Oriental, abarcando rebordos de planalto, depressões interplanálticas, erosivas e tectônicas (gráben) com a presença ou não de cristas estruturais, e blocos soerguidos (horsts). Abarca quatro grandes regiões geomorfológicas (sensu GATTO et al. 1983): (1) Vale do Paraíba do Sul, (2) Planalto Centro Sul de Minas, (3) Mantiqueira Setentrional e (4) Escarpas e Reversos da Serra do Mar, cada uma delas admitindo, no escopo da presente proposta, subdivisões em níveis taxonômicos mais detalhados, conforme desvelado nas figuras 2, 3, 4 e 5. A apresentação quádrupla reflete as limitações de representação de mapeamentos regionais do relevo; a fim de evitar uma apresentação por amostragem e colocar em tela o mapeamento integral, optou-se por decompor o mapa e sua legenda (figuras 6, 7, 8 e 9), cuja 
Marques Neto R. \& Ferraro B. V.

organização em separatas também foi solução para que toda a informação gerada fosse divulgada. Ainda, cabe informar que a porção NW (figura 2) já foi objeto de apresentação pregressa (MARQUES NETO et al. 2016), sendo na presente oportunidade apresentada no contexto geral da cobertura realizada.

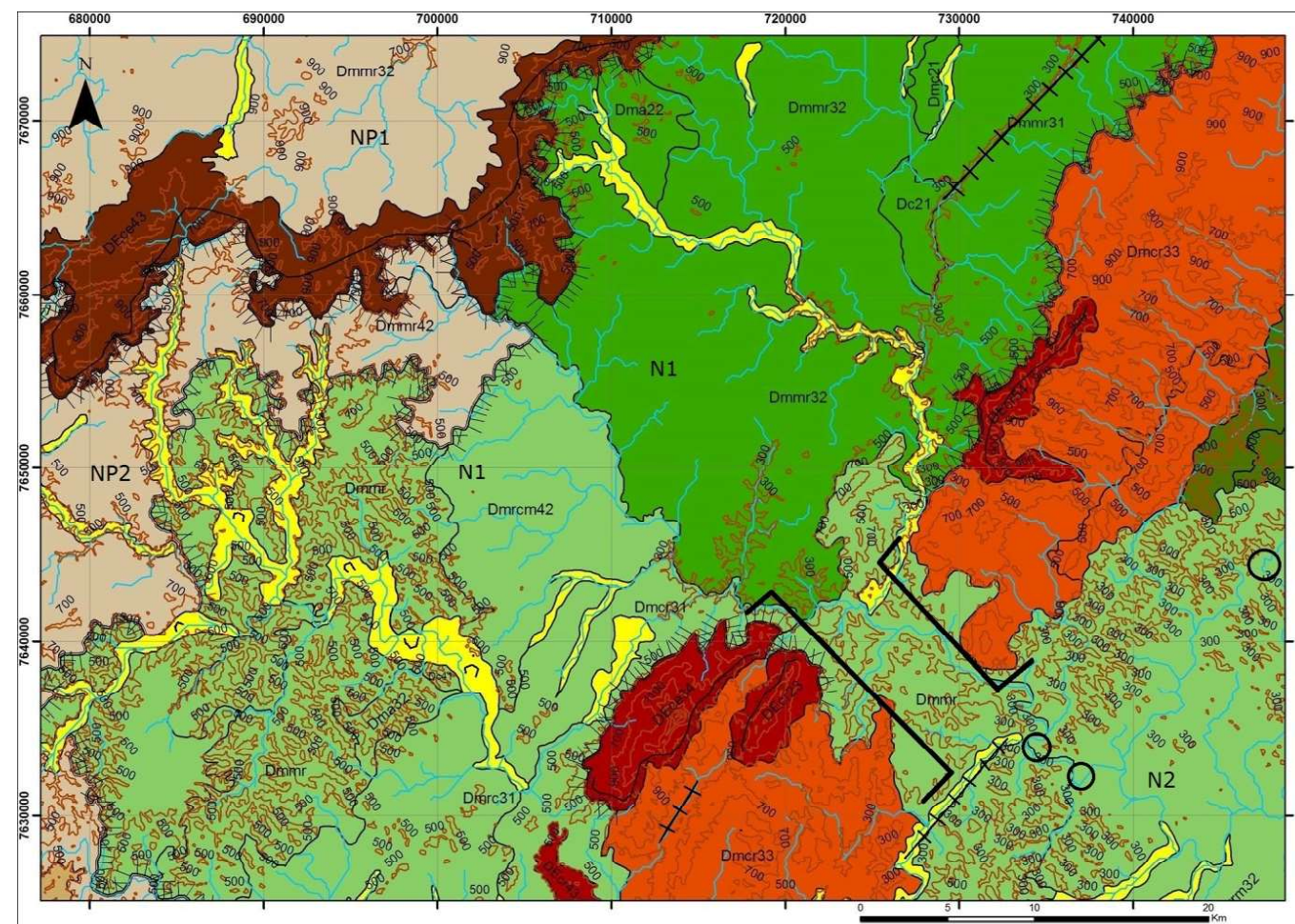

Figura 2 - Carta geomorfológica da Folha Juiz de Fora (1/250.000), porção NW.

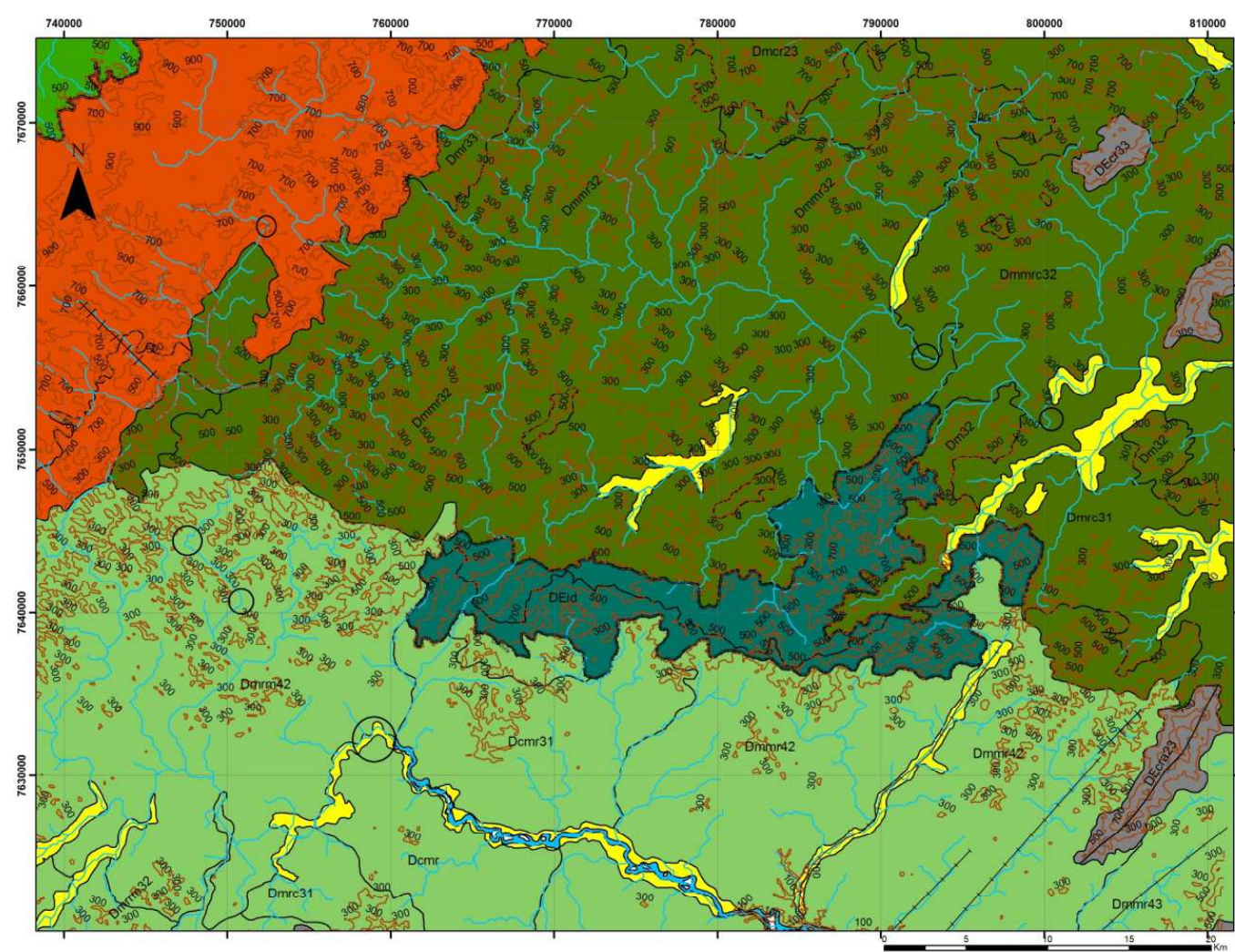

Figura 3 - Carta geomorfológica da Folha Juiz de Fora (1/250.000), porção NE. 
Cartografia Geomorfológica Regional e Morfogênese: Contribuições Metodológicas

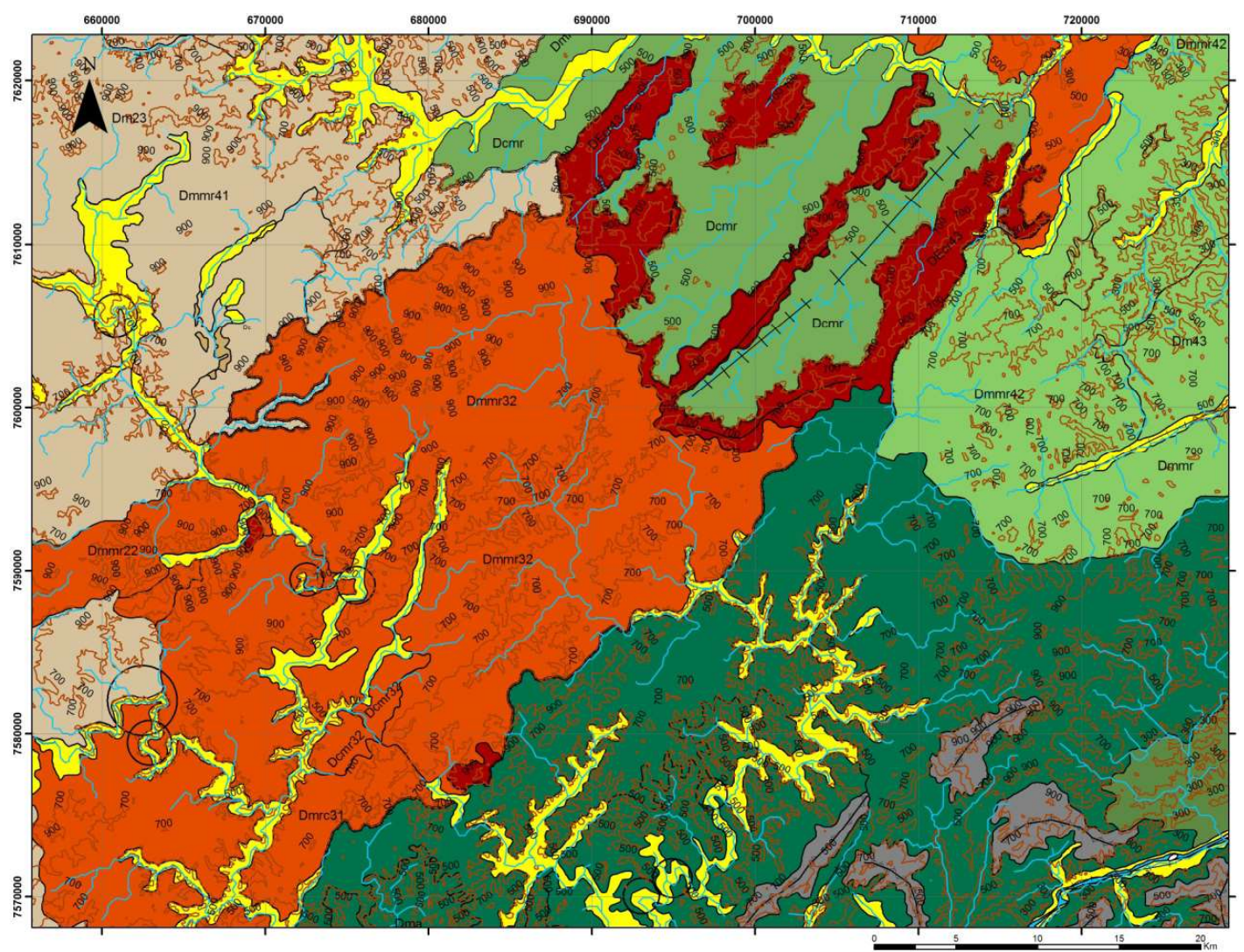

Figura 4 - Carta geomorfológica da Folha Juiz de Fora (1/250.000), porção SW.

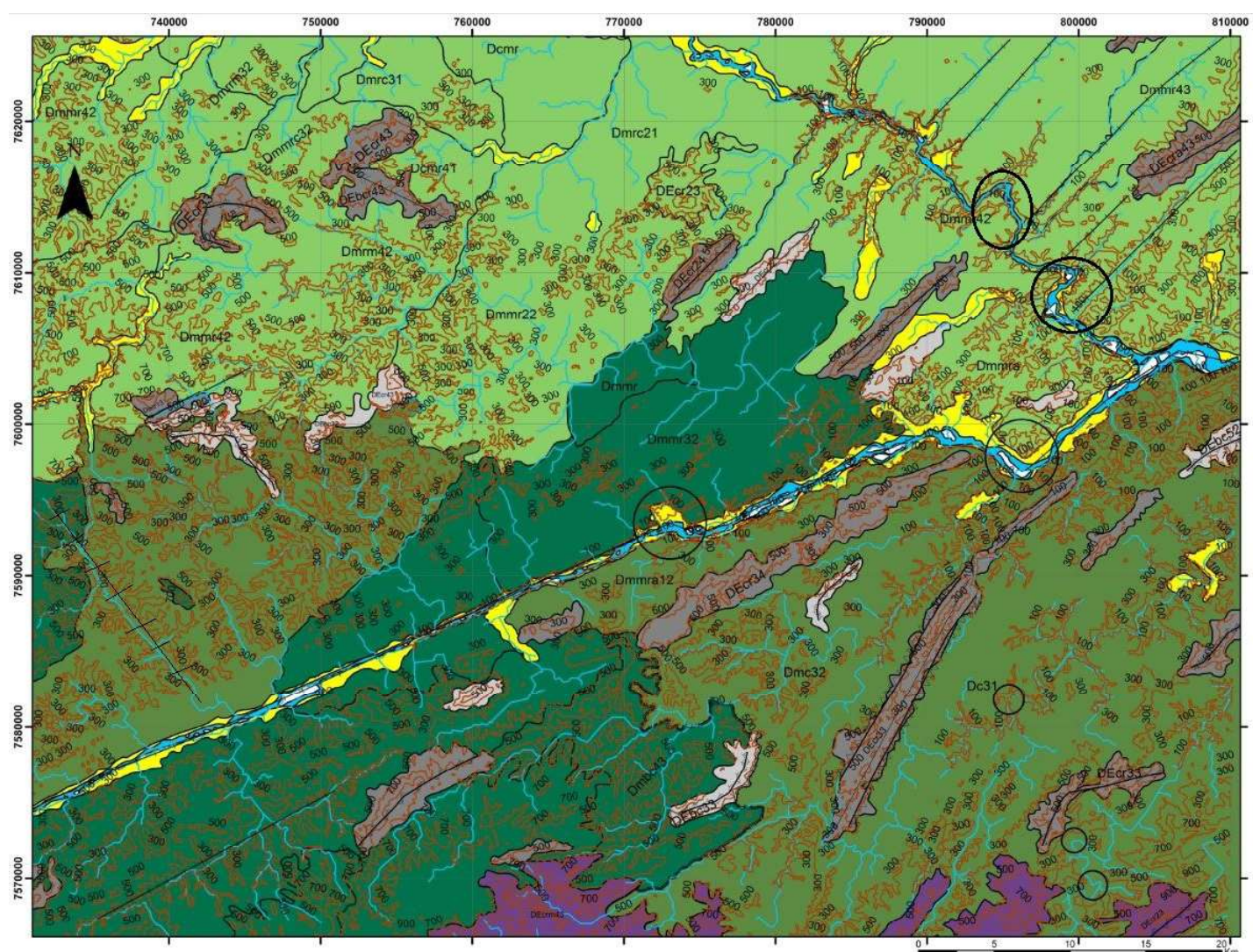

Figura 5 - Carta geomorfológica da Folha Juiz de Fora (1/250.000), porção SE. 


\section{Marques Neto R. \& Ferraro B. V.}

\section{VALE DO PARAÍBA DO SUL}

II. Depressões Interplanálticas Escalonadas do Vale do Paraíba do Sul

III. Depressão do Rio Xopotó

IV. Modelados de Agradação (A)

Apft

Planícies ativas com maior desenvolvimento ao longo do rio Xopotó, associadas ou não a terraços; depósitos neoquaternários de acresção lateral e vertical argilo-arenosos

IV. Modelados de Dissecação Homogênea (D)

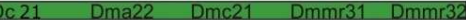

Morros e morrotes convexos com colinas acessórias; topos convexos a aplainados e vertentes convexo-retilíneas com coberturas de alteração argilo-siltosas e profundidade de dissecação moderada; predominio de erosão laminar.

III. Depressăo do Rio Muriaé

IV. Modelados de Agradação (A)

Apft

Planícies ativas descontínuas em função de controle estrutural, com alvéolos intercalados a encaixamentos ao longo do rio Muriaé e desenvolvimento contínuo de destaque nos rios Preto e da Cachoeira; depósitos neoquaternários de acresção lateral e vertical arenoargilosos.

IV. Modelados de Dissecação Homogênea (D)

Morros e morrotes de topos com colinas acessórias; topos convexos a aplainados e vertentes convexo-retilíneas com coberturas de alteração argilo-siltosas e profundidade de dissecação moderada; predominio de erosão laminar.

IV. Modelados de Dissecação em controle estrutural

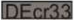

Baixas cristas de orientação geral NE-SW festonadas pela passagem do rio Muriaé na parte média da depressão e altas cristas na mesma orientação desniveladas em torno de 200 metros acima das cristas baixas; linhas interfluviais reafeiçoadas de orientação $\mathrm{E}-\mathrm{W}$.

III. Depressão Escalonada do Rio Pomba

NIVEL I. Depressão do Médio Rio Pomba

IV. Modelados de Agradação (A)

Apft

Planicies fluviais holocênicas bem desenvolvidas em canais meandrantes e faixas de meandros abandonados com dois ou mais niveis de terraços neopleistocênicos a holocênicos.

IV. Modclados do Dissccação Homogênca (D)

Domr 21 Dma52 $\quad$ Dmrom42 Dmor31

Conjuntos de morros e morrotes, contínuos ou associados a colinas. Topos convexos a aplainados e vertentes convexo-retilineas em dissecaçăo moderada; coberturas superficiais argillo-siltosas intensamente latolizadas; predomínio de erosão laminar.

Figura 6 - Legenda $\left(1^{\circ}\right.$ parte $)$

NÍVEL II. Depressão Escalonada do Baixo Rio Pomba

IV. Modelados de Agradação (A)

Apft

Planícies ativas holocênicas descontínuas associadas a dois ou mais níveis de terraços neopleistocênicos a holocênicos, circunstancialmente suprimidas por soerguimentos de blocos e entalhe da drenagem.

IV. Modelados de Dissecaçáo Homogenea (D)

\begin{tabular}{|llllll|}
\hline Dc41 & Dcmr21 & Dcmr31 & Dcmr41 & Dm43 & Dmcr31 \\
Dmmr21 & Dmmr22 & Dmmr42 & Dmmr43 & Dmmra22 & Dmmrc32 \\
Dmrc21 & Dmrc31 & Dmrm42 & Dmrm32 & & \\
\hline
\end{tabular}

Conjuntos de morros e morrotes, contínuos ou associados a colinas. Topos convexos a aplainados e vertentes convexo-retilineas em dissecação moderada: coberturas superficiais argilo-siltosas intensamente latolizadas: predomínio de erosão laminar.

IV. Modelados de Dissecação em controle estrutural (DE)

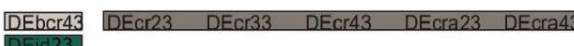

Baixas e altas cristas de orientação geral NE-SW em dissecação profunda; falhas normais controlando inflexões no rio Pomba e a convergência de afluentes, como o rio Novo; coberturas argilo-siltosas pouco espessas, com predomínio de erosão laminar e focos de

III. Depressão do Baixo Rio Paraíba do Sul

IV. Modelados de Agradação (A)

Maior desenvolvimento ao longo do rio Paraíba do Sul, com faixa deposicional neoquaternária argilo-arenosa retilínea em função de expressivo controle estrutural. Alvéolos restritos e descontínuos vinculados a canais tributários.

IV. Modelados de Dissecação Homogênea (D)

Do31 Dmc32 Dmmra12

Morros, morrotes e colinas alongadas com topos aplaianados a convexos e vertentes retilíneo-convexas, alinhados em herança ao controle estrutural regional; padrão de drenagem retangular. Coberturas superficiais argilo-siltosas e predomínio de erosão laminar.

IV. Modelados de Dissecação em controle estrutural

DEbc52 DEcr33

Cristas elevadas e baixas emolduradas em falhas normais de orientaçăo geral NE-SW descontinuas em caráter residual que se sobressaem em depressão etchplanada como anomalias topográficas positivas. Coberturas superficiais argilo-siltosas pouco espessas e predomínio de erosão laminar com focos de erosão concentrada.

III. Cristas do Vale do Paraíba do Sul

IV. Modelados de Agradação (A)

Apft

Planícies ativas e terraços descontínuos em função de controle estrutural, com depósitos neoquaternários de acresção lateral e vertical argilo-arenosos.

IV. Modelados de Dissecação Homogênea (D)

Morros, morrotes e colinas alongadas com topos aplaianados a convexos e vertentes retilíneo-convexas, alinhados em herança ao controle estrutural regional; padrāo de drenagem retangular. Coberturas superticiais argilo-siltosas e predominio de erosāo laminar.

Figura 7 - Legenda $\left(2^{\circ}\right.$ parte $)$. 
Cristas elevadas e baixas emolduradas em falhas normais de orientação geral NE-SW descontínuas em caráter residual que se sobressaem em depressão etchplanada como anomalias topográficas positivas. Coberturas superficiais argilo-siltosas pouco espessas e
predomínio de erosão laminar com focos de erosão

\section{MANTIQUEIRA SETENTRIONAL}

\section{Serranias da Zona da Mata Mineira}

III. Morrarias da Zona da Mata Mineira

IV. Modelados de Agradação (A)

Planicies ativas e terraços descontinuos em função de controle estrutural, com destaque para ao hemigráben do rio Paraibuna e planicie associada em Juiz de Fora; depósitos neoquaternários de acresção lateral e vertical argilo-arenosos.

IV. Modelados de Dissecação Homogênea (D)

Morros e morrotes associados ou não a pequenas colinas de dissecação moderada a profunda com topos aplainados a convexos $e$ vertentes retilíneo-convexas; coberturas superficiais argilo-siltosas, predomínio de erosãolaminar com movimentos de massa recorrentes.

III. Horsts festonados da Mantiqueira Setentrional

IV. Modelados de Dissecação em Controle Estrutural (DE)

Cristas alongadas a escarpadas de orientação geral NE-SW com dissecação profunda e declives pronunciados; coberturas argilo-siltosas pouco espessas com predominio de erosão laminar e focos de erosão concentrada e movimentos de massa recorrentes. Prolongamento a NW da folha em interflúvios reafeiçoados.

III. Escarpas erosivas reafeiçoadas

IV. Modelados de Dissecação em Controle Estrutural (DE)

Escarpas erosivas tectonicamente reafeiçoadas em rebordo de planalto, com vertentes íngremes e profundo entalhe vertical. Coberturas argilosas de desenvolvimento variável com formação de bancadas lateríticas detríticas. Predominio de erosão laminar com focos de movimentos de massa rotacionais e translacionais.

Figura 8 - Legenda $\left(3^{\circ}\right.$ parte $)$.

\section{PLANALTO CENTRO-SUL DE MINAS}

\section{Planalto dos Campos das Vertentes}

III. Planalto Alto Rio Doce

IV. Modelados de Agradação (A)

\section{Apft}

Planicies ativas e terraços descontinuos com sedimentos neoquaternários de acresção vertical e lateral argilo-arenosos.

IV. Modelados de Dissec.ação Homogênea (D)

\section{Dmmr22}

Morros e morrotes de topos convexos a aplainados e vertentes convexo-retilíneas em profundidade de dissecação moderada: coberturas superficiais argilo-siltosas com predomínio de erosão laminar.

III. Planaltos Mamelonares Escalonados

IV. Modelados de Agradação (A) Apft Apfla

Planicies a tivas e terraçus desconlínuos com sedimentus neuquaternárius de acıesção vertical e lateral argill-arenusus.

Planície flúvio-lacustre antropogênica desenvolvida pontualmente vinculada à represamento e modificações nos processos hidrodinâmicos associados.

IV. Modelados de Dissecação Homogênea (D)

Dm23 Dmmr32 Dmmr41

Morros e morrotes de topos convexos a aplainados e vertentes convexo-retilineas em profundidade de dissecação moderada; coberturas superficiais argilo-siltosas com predomínio de erosão laminar.

\section{ESCARPAS E REVERSOS DA SERRA DO MAR}

II. Serra dos Órgãos

IV Modelados de Dissecação em controle estrutural

Reverso retrabalhado parcialmente dissecado em morros alinhados com drenagem adaptada ao controle estrutural, com escalonamento irregular $\Theta$ desnivelamento dos niveis de base locais entre 340 e 400 metros. Coberturas superficiais argilo-siltosas e predomínio de erosão laminar com movimentos de massa recorrentes.

INDICES DE DISSECAÇÃO DO RELEVO

\begin{tabular}{|l|c|c|c|c|c|}
\hline $\begin{array}{l}\text { Intensidade de ental he } \\
\text { vertical da drenagem }\end{array}$ & $\begin{array}{c}\text { Muito Fina } \\
(<400 \mathrm{~m})\end{array}$ & $\begin{array}{c}\text { Fina } \\
(401 \mathrm{a} 600 \mathrm{M})\end{array}$ & $\begin{array}{c}\text { Média } \\
(601 \mathrm{a} 800 \mathrm{M})\end{array}$ & $\begin{array}{c}\text { Grosseira }(801 \\
\mathrm{a} 1000 \mathrm{~m})\end{array}$ & $\begin{array}{c}\text { Muito Grosseira } \\
(>1000 \mathrm{~m})\end{array}$ \\
\hline Muito Fraca $(<100 \mathrm{~m})$ & 5.1 & 4.1 & 3.1 & 2.1 & 1.1 \\
\hline Fraca $(101 \mathrm{a} 200 \mathrm{~m})$ & 5.2 & 4.2 & 3.2 & 2.2 & 1.2 \\
\hline Mediana $(201 \mathrm{a} 500 \mathrm{~m})$ & 5.3 & 4.3 & 3.3 & 2.3 & 1.3 \\
\hline Forte $(501 \mathrm{a} 1000 \mathrm{~m})$ & 5.1 & 1.1 & 3.1 & 2.1 & 1.1 \\
\hline Muito Forte $>1000 \mathrm{~m})$ & 5.5 & 4.5 & 3.5 & 2.5 & 1.5 \\
\hline
\end{tabular}

Apfla - Planicie Flúvio Lacustre Antropogênica Apflt-Planicies Fluviais e Terraços

$$
\begin{aligned}
& \mathrm{C}-\text { Colinas } \\
& \mathrm{m}-\text { Morros }
\end{aligned}
$$

m-Morros

$\mathrm{mr}$-Morrotes

bcr-Baixas Cristas

cr - Cristas Simétricas a Assimétricas

ce - Cristas Erosivas e Escarpas

id - Interflúvios Estreitos Dissecados

\begin{tabular}{|c|c|}
\hline & SIMBOLOGIA \\
\hline 0 & Anomallas de Drenagem \\
\hline & Cristas Assimétricas \\
\hline & Cristas Simétricas \\
\hline & Curvas de Nível \\
\hline & Escarpas \\
\hline & Gargantas Epigênicas \\
\hline & Ilhas Fluviais \\
\hline CD & Meandros Abandonados \\
\hline 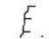 & Rebordo Erosivo \\
\hline & Vales Estruturais \\
\hline
\end{tabular}

Figura 9 - Legenda $\left(4^{\circ}\right.$ parte $)$ 
Marent e Valadão (2015) apresentam uma proposta de compartimentação geomorfológica para o sudeste de Minas Gerais que em parte se sobrepõe à área de estudo. Os autores firmaram sua proposição fundamentalmente pelo critério altimétrico afeitos às relações reconhecidas entre as seções hipsométricas e as organizações topográficas regionais, diferenciadas segundo degraus topográficos nominados por Degrau Paraná-São Francisco, Degrau Doce e Degrau Paraíba do Sul, que de forma geral apresentam decréscimo altimétrico de oeste para leste. Os compartimentos que os autores retrocitados designam por Degrau Doce e Paraíba do Sul dialogam estreitamente com algumas das unidades geomorfológicas interpretadas e posteriormente discutidas mais detalhadamente em seus aspectos genéticos e evolutivos.

$\mathrm{Na}$ extremidade oeste posiciona-se o rebordo do Planalto Centro Sul de Minas em dois compartimentos de desnivelamento bem marcado no Planalto de Campos das Vertentes: (1) Planalto do Alto Rio Doce, que ultrapassa $900 \mathrm{~m}$ de altitude na extremidade NW da folha, (2) Planalto Escalonado do Campo das Vertentes, estabelecido em pronunciado desnivelamento em relação ao compartimento anterior da ordem de $200 \mathrm{~m}$, subnivelando em torno de $700 \mathrm{~m}$ de altitude e ascendendo além de $900 \mathrm{~m}$ de forma descontínua em contextos de maior controle estrutural. Os pisos deste segundo nível planáltico encontram-se aquém de $500 \mathrm{~m}$ de altitude em função da vaga erosiva remontante do rio Pomba, que abre expressiva depressão interplanáltica subsequente cujo limite oeste estabelece contato erosivo com os compartimentos do Planalto Centro Sul de Minas. Tais unidades correspondem ao que Marent e Valadão (2015) generalizam como Degrau Doce (Unidade II).

A Depressão do Rio Pomba partilha de uma rede de depressões interplanálticas do Vale do Rio Paraíba do Sul, controladas por diferentes níveis de base regionais que se escalonam em demanda ao principal nível de base marcado pela passagem do rio homônimo, tributário direto do Oceano Atlântico. A própria depressão do rio Pomba pode ser compartimentalizada em dois níveis elementares, sendo o primeiro posicionado em torno de $500 \mathrm{~m}$ acima do nível do mar no contato com o planalto, decaindo em torno de $200 \mathrm{~m}$ à jusante da garganta epigênica que o rio em questão abre entre os pilares tectônicos da Serra da Mantiqueira; por último, o rio Pomba aloja-se em restrito bloco abatido em torno de $100 \mathrm{~m}$ de altitude já nas proximidades de sua confluência na margem esquerda do rio Paraíba do Sul, sinalizando provável reativação de estruturas antigas. Este importante tronco coletor figura como nível de base para o sistema drenado pelos rios Ubá e Xopotó, cujas afluências são controladas pelo horst da Mantiqueira Setentrional. Na colateral NE, a Depressão do Rio Muriaé se dispõem escalonada com desnivelamento paulatino no sentido N-S, até definir sua afluência no rio Paraíba do Sul a leste da folha aqui interpretada.

Os sistemas depressionários são truncados pelos pilares tectônicos (horsts) que atravessam a porção central da Folha Juiz de Fora no sentido NE-SW, e que pertencem à Mantiqueira Setentrional, em alinhamento de cristas acima de 900 metros de altitude e morros profundamente dissecados influenciados pelo sistema rifte continental do sudeste do Brasil (RICCOMINI, 1989), com sinais de reativações posteriores, figurando como importante zona de cisalhamento regional que afeta diferentes litotipos. Os alinhamentos são bem definidos, e o controle estrutural da drenagem bastante evidente, pelo qual os canais estruturalmente controlados estabelecem confluências ortogonais com os rios Pomba e Novo, superimpostos às cristas estruturais NE-SW mediante a abertura de gargantas epigênicas que resultaram em significativo festonamento do horst. No extremo SE da folha outro sistema horst se projeta no reverso escalonado da Serra dos Órgãos, que ocupa um quinhão restrito da área abrangida pelo mapeamento.

Entre os dois domínios de soerguimento aloja-se o gráben do rio Paraíba do Sul, que perpassa a porção sudeste da área de estudo em controle estrutural bem marcado, perfazendo consideráveis extensões em retilinidade anômala que se adéqua ao sentido dominante do rifte (NE-SW), com circunstanciais inflexões para SE em resposta a controles morfotectônicos mais recentes, definindo-se assim um segmento caracterizado por anomalias de drenagem de forte evidência. Nesse contexto de maior controle as planícies fluviais são retilíneas, sendo comum o desenvolvimento de tipicidade fluvial em braided, com ampla formação de ilhas fluviais. O rio Paraíba do Sul disseca relevos convexos do tipo "mar de morros", nivelados em torno de 500 metros nas proximidades da Mantiqueira Setentrional, e decaindo altimetricamente no sentido leste, consubstanciando-se um aspecto depressionário na margem direita, onde avulta uma topografia mais colinosa e dissecação mais branda que se rebaixa aquém 
de 100 metros de altitude. Também na margem direita se escalonam os primeiros patamares interiores da Serra dos Órgãos, já no contexto da Serra do Mar.

\section{Aspectos da morfogênese regional: interpretações a partir da cartografia geomorfológica}

As organizações geomorfológicas regionais que se projetam na Folha Juiz de Fora se diferenciam mediante uma diversidade digna de nota, engendrada pelos diferentes contextos morfogenéticos e litoestruturais dos compartimentos que ali se encontram, cuja gênese e evolução remetem a diferentes processos geodinâmicos ligados a controles estruturais e morfotectônicos que legaram, em consonância às influências climáticas atuais e pretéritas, diferenciações nos processos denudacionais e agradacionais cenozoicos, enfaticamente os quaternários. Compartimentos residuais de planalto, depressões erosivas e tectônicas (grábens) com morfologias convexas e pilares tectônicos (horsts) emoldurados em cristas retilíneas ligadas ao rifteamento plataformal e sucessivamente reativadas figuram como os compartimentos fundamentais do relevo na área de estudo.

A extremidade oeste da folha Juiz de Fora coincide com o contato erosivo entre as depressões interplanálticas que se orientam em demanda ao Oceano Atlântico e o Planalto Centro Sul de Minas, amplamente dissecado em sua borda pela entrada da rede hidrográfica pertencente à bacia do rio Paraíba do Sul e do rio Doce, sendo a faixa interfluvial estabelecida por um prolongamento da Mantiqueira dado por um alto esporão recuado, estreito e profundamente dissecado que adentra o planalto perfazendo a linha divisória de águas; embora não apresente um controle morfotectônico tão exacerbado como ocorre nas escarpas meridionais, o relevo apresenta elevada energia, com entalhe vertical significativo e desenvolvimento de facetas triangulares e trapezoidais em mais de um nível das escarpas escalonadas. Nesses níveis de cimeira que definem a passagem para o Planalto de Campos das Vertentes podem ser encontrados perfis lateríticos autóctones preservando patamares, alguns deles de aspecto cascalhento, sugerindo certa maturidade, indicada pela fragmentação de couraças contínuas preexistentes. No domínio das vertentes, por seu turno, os canais entalham profundamente, e os processos erosivos são intensos, incluindo escorregamentos rotacionais e translacionais, queda e rolamento de blocos e expressivo coluvionamento, com intenso retrabalhamento em vales confinados a semiconfinados que não aportam tratos deposicionais expressivos, promovendo assim uma rápida transferência para as depressões, onde as morfologias agradacionais são bem desenvolvidas e os vales evoluídos.

A entrada erosiva agressiva das bacias hidrográficas que vertem ao Atlântico vem provocando dissecação e recuo dos divisores nesta zona de justaposição. Os contatos erosivos nestas bordas interplanálticas tem desdobramentos contundentes na evolução das linhas interfluviais em função dos conspícuos processos de captura fluvial, discutidos por Cherem et al. (2013) a partir de estudo realizado em três contextos distintos em diferentes estágios de evolução, todos eles distribuídos pelas faixas de contato entre os planaltos interiores e as depressões interplanálticas exorreicamente drenadas. Os autores concluem que a maior agressividade erosiva das bacias que drenam na direção leste, controladas por um nível de base mais baixo, faz com que este seja o sentido dominante das capturas, o que repercute no aumento progressivo das bacias captoras (Paraíba do Sul, Doce, etc.) à custa do consumo de nacos das bacias capturadas nos níveis planálticos superiores (Paraná, São Francisco). As lateritas encontradas nos domínios altimontanos que estabelecem as faixas interfluviais entre as depressões e as bacias do rio Grande e rio Doce contribuem, em alguma medida, na sustentação destes estreitos divisores, já pronunciadamente recuados e obliterados pela entrada erosiva do rio Pomba e afluentes.

As depressões erosivas que se abrem evoluem a partir do controle regional dado pelo rio Paraíba do Sul, nível de base direto para os rios Pomba e Muriaé e indireto para importantes eixos fluviais como o rio Novo, Ubá e Xopotó, que também se relacionam a compartimentos depressionários. A força erosiva do rio Pomba, Xopotó e Novo deu conta de escavar gartantas epigênicas nos alinhamentos da Mantiqueira Setentrional, que intercepta a parte central da folha no sentido geral NE-SW pronunciadamente festonada. Oliveira et al. (2014), interpretando a morfologia dos vales dos rios que escavam os alinhamentos, não registram evidências cartográficas da existência de lineamentos antigos controlando o corte epigênico, o que sugeriria que os períodos erosivos predominariam a mais tempo e estariam associados às movimentações não 
contínuas do horst, mas que perdurariam até o Holoceno, conforme também fora apontado por Noce et al. (2003). Fortes indícios acerca da referida dinâmica ascencional seriam dados pela sequência de saltos e corredeiras que eclodem quando tais rios dissecam os pilares tectônicos sucessivamente reativados. De qualquer forma, alguns elementos ficam em aberto, e a datação dos depósitos correlativos que preenchem os fundos de vale tanto no planalto como nas depressões deverá trazer informações conjuntivas para a interpretação destas organizações geomorfológicas.

O controle morfotectônico atuando nas depressões interplanálticas e influenciando seus esquemas erosivos e deposicionais tambémé sugerido pelo desnivelamento no interior dos compartimentos depressionários, o que resulta em dois níveis altimétricos para a Depressão do Rio Pomba: um a oeste dos pilares tectônicos em torno de 500 metros de altitude e outro posicionado na direção cardial leste em altitudes médias de 300 metros, num desnível que abarca consideráveis 200 m. A Depressão do Rio Xopotó encontra-se quase toda no nível mais elevado e começa a ser incipientemente mordida pela evolução erosiva na base do corte epigênico. Em trabalho clássico sobre o relevo da Zona da Mata Mineira, Valverde (1958) denomina a superfície mais elevada a oeste dos alinhamentos da Mantiqueira de Superficie Guarani, e aquela que se abre a leste, mais rebaixada e de maior extensão, de Superficie Leopoldina, a qual reconheceu como o compartimento geomorfológico que estabelece as relações mais estreitas com a Zona da Mata Mineira. Reconheceu ainda as superfícies planálticas residuais que marcam as linhas interfluviais com o Planalto Centro Sul de Minas, as quais chamou de Superfície Ervália, que se estabelece nos topos remanescentes da Mantiqueira, e que o autor estabeleceu a partir de uma correlação com a Superfície Sul-americana de King (1956), dada pelos somitais de volumetrias topográficas de destaque como a serra da Boa Vista e do Relógio e pelas cimeiras interfluviais que definem a linha divisória das bacias do rio Paraíba do Sul e Doce, e que descamba em escarpas erosivas intensamente retrabalhadas pelos canais da alta bacia do rio Pomba e do ribeirão Ubá.

Os dois níveis existentes na Depressão do rio Pomba são caracterizados por morfologias semelhantes, fracamente dissecadas e padronizadas em morros, morrotes e pequenas colinas marcadamente convexos e com coberturas superficiais argilosas francamente latolizadas. $\mathrm{O}$ desnivelamento em questão se deu por esforços diastróficos neotectônicos influenciados pelo próprio soerguimento do horst, que pode ter favorecido o estabelecimento de um nível mais elevado para a Depressão do Rio Pomba. Nesse caso, as superfícies designadas por Guarani e Leopoldina por Valverde (1958) corresponderiam a uma mesma superfície do ponto de vista genético e cronológico, forjada ao longo de processos de dissecação plio-pleistocênicos, porém desniveladas altimetricamente em função das solicitações tectônicas recentes.

Dessa forma, a passagem dos alinhamentos da Mantiqueira determina contextos evolutivos distintos para os dois níveis depressionários, limitados por soleiras. Soerguida na retaguarda do horst da Mantiqueira, a porção oeste da Depressão do Rio Pomba, a mais elevada, apresenta dois níveis bem marcados de terraço e ampla formação de diques marginais sempre que são abertas bacias de inundação descontínuas, o que também indica um controle morfotectônico contundente revelado pelo forte entalhe e abrasão de sedimentos fluviais, bem como pela intercalação de segmentos de drenagem encaixada com extensões de planícies ativas. Os níveis de terraço mencionados foram reconhecidos e estudados detalhadamente por Oliveira (2012), que ainda discerniu um terceiro e, em alguns contextos, um quarto nível de terraços já reafeiçoados por processos erosivos de vertente. Os níveis de base locais têm favorecido a agradação das depressões, que têm acolhido os depósitos correlativos à denudação das superfícies de cimeira que se estabelecem a partir do reverso das escarpas. Antonioli et al. (2005), a partir de dados palinológicos obtidos pontualmente, apontaram idades posicionadas entre o Mioceno e o Plioceno para os depósitos em questão, o que nos faz sugerir que o estabelecimento das linhas interfluviais da bacia do rio Pomba retroceda ao Oligoceno, na primeira fase de reativação do rifte continental, ainda precedente ao corte epigênico imposto ao horst da Mantiqueira e tendo referência no rio Paraiba do Sul já estabelecido como nível de base regional. As análises palinológicas foram levadas a efeito pelos autores supracitados em corpos deposicionais localizados no município de Recreio (MG), posicionados, portanto, a leste dos pilares tectônicos (nível mais baixo da Depressão do Rio Pomba) que deveriam marcar as antigas linhas interfluviais do rio Pomba anteriormente à sua superimposição. 
As planícies fluviais mais expressivas da Folha Juiz de Fora a oeste dos alinhamentos da Mantiqueira Setentrional correspondem àquelas abertas pelo rio Pomba e, secundariamente, pelo rio Novo, sendo que ambos iniciam o desenvolvimento de morfologias agradacionais ainda nos níveis superiores do Planalto de Campos das Vertentes, perfazendo tipicidades meandrantes de sinuosidade variável nos níveis depressionários, com desenvolvimento de faixas de meandros abandonados. Na direção a leste dos pilares tectônicos as planícies ficam mais descontínuas e o controle estrutural imposto pelo sistema rifte emerge de forma explícita a perdurar até o ambiente plataformal, forçando um alinhamento bem marcado no sentido NESW para o relevo e drenagem, a exemplo do controle anômalo exercido no rio Paraíba do Sul. Uma série de afluentes deste e do rio Pomba no baixo curso define um padrão de drenagem retangular marcado por vales estruturais pronunciadamente retilíneos cujos canais fluviais estabelecem confluências ortogonais com os principais troncos coletores.

Dos altos pilares tectônicos às depressões rebaixadas, entende-se que os aspectos geomorfológicos fundamentais da Folha Juiz de Fora se sumarizam em um nível representativo das cimeiras regionais entre $700 \mathrm{e}$ 1000 metros e três níveis intermontanos que se nivelam, de oeste para leste, em faixas altimétricas de 500, 300 e 100 metros. Os níveis superiores correspondem ao planalto erosivo, aos pilares tectônicos e algumas cristas estruturais, definindo assim contatos tanto erosivos como tectônicos. Os compartimentos do Planalto de Campos das Vertentes estabelecem contato erosivo com o primeiro nível intermontano, que doravante se escalona em controle morfotectônico em demanda ao rio Paraíba do Sul, o que se revela em entalhes epigênicos, inflexões abruptas de canais fluviais em muitos casos vinculadas a falhas transcorrentes e outras evidências francamente sobrepostas a feições estruturais herdadas da reativação correlata ao rifte sudeste. Os contatos erosivos e tectônicos, juntamente às feições passivas remanescentes e aos fatos geomórficos morfotectônicos, revelam de forma contundente a variação regional das forças geomorfológicas.

\section{Conclusões}

Os mapeamentos regionais do relevo, ao atender integridades escalares postadas nessa grandeza, admitem a inserção mais contundente de determinadas informações em detrimento de outras. No concernente aos aspectos morfogenéticos e morfológicos, obtevese uma representação resoluta dada pelos padrões de formas, integralizados a partir dos diferentes tipos genéticos, denudacionais e agradacionais, cuja combinação materializa as grandes unidades regionais do relevo. A morfometria, tal como os dois aspectos anteriormente mencionados, também admite um trato generalizado e abrangente para toda a área, uma vez que tais informações são extraídas diretamente das bases planialtimétricas oficiais, possibilitando uma combinação adequada de famílias de cores e símbolos unificadores de aspectos morfológicos e morfométricos. Pela mesma pauta, dados morfoestruturais também são facilmente incorporáveis pelo uso de simbologias específicas, desde que estabelecidos para áreas cujo controle mantém expressão espacial compatível com a escala. A morfodinâmica, no entanto, teve sua representação derivada do trato morfométrico com base na matriz de dissecação, reforçada por poucos símbolos; fatos geomórficos como ravinas, voçorocas e cicatrizes de escorregamento, deveras pontuais, acabam tendo sua representação obstaculizada em mapeamentos regionais. Não menos, a base geológica foi omitida em função do número expressivo de grupos ocorrentes na área, diversificados em uma plêiade de litotipos que facilmente extrapolariam os recursos gráficos cabíveis em um documento cartográfico resoluto; definitivamente, combinações com hachuras de fundo ou tabela de cores à parte foram opções que se revelaram inexequíveis. Finalmente, o problema da cronologia possivelmente seja amiúde o mais crônico, em função da própria dificuldade em se datar o relevo. Nesse sentido, ou os trabalhos em cartografia geomorfológica se aproximam dos procedimentos de datação absoluta, como Luminescência Opticamente Estimulada (LOE) para depósitos quaternários e fissão em apatita e técnicas afins em superfícies mais antigas (o que muitas vezes é financeiramente inviável, e tende a ser cada vez mais em tempos de cortes orçamentários para a pesquisa), ou continuarão trazendo informações geocronológicas relativas, um tanto especulativas, e acessórias às demais.

$\mathrm{O}$ enfoque genético é que constitui a base fundamental da cartografia geomorfológica regional, cuja informação básica remete à gênese e evolução do relevo na região mapeada, diferenciando os compartimentos, fundamentalmente, por tais aspectos. 
Para tal, a escala de $1 / 250.000$ se mostrou bastante adequada para a interpretação de tais integridades, revelando os tipos genéticos fundamentais em suas formas e métricas, a natureza dos contatos e aspectos inerentes ao controle morfoestrutural e morfotectônico, propiciando um detalhamento efetivo do quadro geomorfológico regional em relação ao mapeamento ao milionésimo do RADAMBRASIL. O território brasileiro ainda padece de uma cobertura mais detalhada dos seus sistemas geomorfológicos regionais, e os trabalhos esparsos ainda dão a tônica do estado da arte da disciplina. A ampliação dos mapeamentos geomorfológicos com vistas em articulações e correlações regionais, portanto, é altamente desejável na agenda da cartografia geomorfológica, seja pela justaposição de folhas topográficas, pelo mapeamento em bacias hidrográficas, das grandes unidades de relevo, municípios, ou outras referências espaciais.

Uma vez pautada em um enfoque genético, uma linguagem metodológica para a cartografia geomorfológica regional pode ser proposta, pelo menos a título de opção, em conformidade ao apresentado, que, partindo de sistemas metodológicos preexistentes, obteve como resultado um documento cartográfico e sua respectiva legenda em formato suficientemente resoluto e explicativo, trazendo ainda como ganho científico o estabelecimento de mais dois níveis taxonômicos ao relevo regional além das regiões e unidades geomorfológicas que o mapeamento ao milionésimo abarcou. É crível que uma perspectiva de uniformização, pelo menos por ensejo, se consubstancia pela abrangência deste protocolo metodológico em sua aplicabilidade para outras regiões e sistemas geomorfológicos tratados em escala regional, potencializando o entendimento mais detalhado das grandes unidades de mapeamento do relevo brasileiro estabelecidas por projetos como o RADAMBRASIL ou órgãos como o Instituto Brasileiro de Geografia e Estatística (IBGE). Por outro lado, a estrutura metodológica não é hermética, uma vez que admite adaptações na organização taxonômica e, principalmente, na representação por símbolos, tal como as matrizes metodológicas das quais esteve embebida. Diante disso, é factível e salutar que as coberturas regionais se pautem em uma estrutura metodológica de ampla aplicação que ao mesmo tempo seja suficientemente aberta para permitir as adequações demandadas pelas especificidades existentes nas grandes unidades geomorfológicas.

\section{Referências Bibliográficas}

ANTONIOLI, L.; TUPINAMBÁ, M.; GRACIA, M. J. DINO, R. Palinologia e idade de sedimentos neógenos (Mioceno Superior/Plioceno) da depressão do rio Pomba-Muriaé (MG). In: SIMPÓSIO DE GEOLOGIA DO SUDESTE, 2005, Rio de Janeiro. Anais... Rio de Janeiro, 2005. p. 63

BARBOSA, G. V. Evolução da metodologia para mapeamento geomorfológico do Projeto RADAMBRASIL. Geociências, v. 2, p. 7-20, 1983.

CHEREM, L. F.; VARAJÃO, C. A. C.; MAGALHÃES JR., A. P.; VARAJÃO, A. F. D. C.; SALGADO, A. A. R.; OLIVEIRA, L. A. F.; BERTOLINI, W. Z. O papel das capturas fluviais na morfodinâmica das bordas interplanálticas do sudeste do Brasil. Revista Brasileira de Geomorfologia, v. 14, n. 4, p. 299-308, 2013.

CUNHA, C. M. L. A cartografia geomorfológica em áreas litorâneas. Tese (livre docência em Geografia). Instituto de Geociências e Ciências Exatas, Universidade Estadual Paulista. Rio Claro, 2012. 119p.

EVANS, I. S. Geomorphometry and landform mapping: what is a landform? Geomorphology, v. 137, p. 94-106, 2012.

GATTO, L. C. S.; RAMOS, V. L. S.; NUNES, B. T. A.; MAMEDE, L.; GÓES, M. H. B.; MAURO, C.A.;ALVARENGA, S. M.; FRANCO, E. M. S.; QUIRICO, A. F.; NEVES, L. B. Geomorfologia. In: Projeto RADAMBRASIL. Folha SF-23/24 Rio de Janeiro/Vitória. Rio de Janeiro: IBGE, 1983.

GUSTAVSSON, M.; KOLSTRUP, E. New geomorphological mapping system used at different scales in a Swedish. Geomorphology, n. 110, p. 37-44, 2009.

KING, L. C. A Geomorfologia do Brasil Oriental. Revista Brasileira de Geografia, v. 18, p. 147-265, 1956.

MARENT, B. R.; VALADÃO, R. C. Compartimentação geomorfológica dos planaltos escalonados do sudeste de Minas Gerais - Brasil. Revista Brasileira de Geomorfologia, v. 16, n. 2, p. 255-269, 2015.

MARQUES NETO, R.; FERRARO, B. V.; ZAIDAN, R. T. Cartografia geomorfológica regional aplicada ao estudo da evolução do relevo em bordas planálticas: aplicações no setor NW da Folha Juiz de Fora (1/250.000). In: XI SIMPÓSIO NACIONAL DE GEOMORFOLOGIA, 2016, Maringá Anais... Maringá, 2016.

NOCE, C. M.; ROMANO, A. W.; PINHEIRO, C. M.; MOL, V. S.; PEDROSA-SOARES, A. C.. Folha Ubá - SE.X-D-II. In: 
COMIG - Projeto Leste, 2003.

NUNES, B. A.; RIBEIRO, M. I. C.; ALMEIDA, V. J.; NATALI FILHO, T. Manual técnico de geomorfologia. Rio de Janeiro: IBGE, 1994. 113p. (Série Manuais Técnicos em Geociências, n. 5).

OLIVEIRA, L. A. F. A dinâmica fluvial quaternária e a configuração do modelado do relevo no contato entre a Depressão do Rio Pomba e o Planalto de Campos das Vertentes. Dissertação (mestrado em Geografia). Instituto de Geociências, Universidade Federal de Minas Gerais. Belo Horizonte, 2012. 224p.

OLIVEIRA, L. A. F.; MAGALHÃES JR. A, P.; LIMA, L. B. S.; CARVALHO, A. Fatores condicionantes da configuração dos fundos de vale colmatados na bacia do alto-médio rio Pomba, leste de Minas Gerais. Revista Brasileira de Geomorfologia, v. 15, n. 4, p. 639-657, 2014.

RICCOMINI, C. O rift continental do sudeste do Brasil. Tese (doutorado em Geologia Sedimentar), Instituto de Geociências, Universidade de São Paulo, São Paulo, 1989. 256p.

ROSS, J. L. S. O registro cartográfico dos fatos geomórficos e a questão da taxonomia do relevo. Revista do Departamento de Geografia, n. 6, p. 17-29, 1992.

TRICART, J. Principés et méthods de la géomorphologie. Mason: Paris, 1965. 496p.

VALVERDE, O. Estudo regional da zona da mata de Minas Gerais. Revista Brasileira de Geografia, v. 20, n. 1, p. 1-82, 1958.

VERStAPPEN, H. T. Applied Geomorphology. Elsevier: Amsterdam, 1983. 437p. 